\title{
Kinetics of Plasmodium falciparum Gametocyte Sex Ratios: Application to the Evaluation of the Potential of Antimalarial Drugs to Influence Malaria Transmission
}

\author{
Grace O. Gbotosho, Akintunde Sowunmi* and Christian T. Happi \\ Department of Pharmacology and Therapeutics and Institute for Medical Research and Training, University of Ibadan, \\ Ibadan, Nigeria
}

\begin{abstract}
A non-compartment pharmacokinetic model was used to evaluate the potential of antimalarial drugs to influence malaria transmission using the ratio of sex specific gametocyte half-lives male:female- the gametocyte maleness index (GMI), and the ratio of the sex specific area inscribed by the plot of gametocyte sex density versus time curves AUCmg:AUCfg- the gametocyte maleness load index (GMLI). Data on gametocyte sexes collected in children with symptomatic Plasmodium falciparum malaria who were treated with various antimalarial drugs in an endemic area were examined using the two indices. Both GMI and GMLI were positively correlated $(r=0.71, \mathrm{P}<0.0001)$ and with $95 \%$ limits of agreement of -9.7 to 13.8 using Altman-Bland plot. Based on the assumption that, a male-biased sex ratio, if gametocytaemia is low, may increase mosquito infectivity, both GMI and GMLI, consistently gave index ratios $>1$ for 4aminoquinolines and antifolates suggesting potential for increasing the chance of mosquito infectivity. By contrast, artesunate and artemisinin-based combination therapies (ACTs), artemether-lumefantrine, and artesunate-amodiaquine, and a non-ACT, amodiaquine plus sulfalene-pyrimethamine, had ratios $<1$ suggesting potential for reducing the chance of mosquito infectivity. The advantages and drawbacks of using these indices as tools in assessing the influence of antimalarials on transmission potentials in endemic areas of malaria are discussed.
\end{abstract}

Keywords: P. falciparum, gametocytes, sex ratio, transmission, antimalarials, children, Nigeria.

\section{INTRODUCTION}

Gametocytes, the sexual forms of Plasmodium spp., are essential for the transmission of the parasite from the vertebrate host to humans by mosquitoes obtaining a human blood meal and for the infectivity of the vertebrate host obtaining the blood meal. Mosquito infectivity after a blood meal can be influenced by a number of factors including gametocyte density [1], their sex ratios [2,3] defined as the proportion of peripheral gametocytes that are male [4], and the type of antimalarials used [5-7].

If the transmission success of Plasmodium spp. is threatened by host and other factors, the parasite may respond by investing in more gametocyte production, for example, $P$. chabaudi or by increasing the sex ratio of its gametocytes, for example, P. vinckei petteri [8]. Recent studies have shown that in human malarias, antimalarials may increase gametocyte production and sex ratios, for example, in vitro and in vivo by $P$. falciparum [9-12].

Current methods for evaluation of mosquito infectivity after a blood meal have employed detection and estimates of sporozoites load in laboratory bred, human blood fed mosquitoes $[2,6,7,13]$. Although these methods are adequate and can be used to assess the influence of antimalarials on mosquito infectivity [7] they are laborious, time con-

*Address correspondence to this author at the Department of Clinical Pharmacology, University College Hospital, Ibadan, Nigeria; Tel: +2348023359390; E-mail: akinsowunmi@hotmail.com suming and require considerable expertise and may not be optimal in epidemiological settings. In addition, mosquito infectivity studies have not employed pharmacokinetic principles. If gametocyte sex ratio is crucial to mosquito infectivity and, if antimalarials significantly alter gametocyte density and sex ratio, then there is an urgent need to explore alternative, simple, and complimentary methods for the evaluation of the potential of antimalarial drugs to influence malaria transmission in epidemiological settings. Further more, transmission is a dynamic process and residents of endemic areas constantly self medicate for imagined or proven malaria infections.

In order to address these issues in an area of intense transmission, we have developed new indices based on pharmacokinetic principles, for assessing the influence of antimalarial drugs on gametocyte sexes and used them to evaluate the potential of these drugs to enhance or reduce malaria transmission. The indices are based on the assumption that male-biased gametocyte sex ratio is crucial to mosquito infectivity [2], particularly when gametocytaemia is low $(<10 / \mu 1$ blood) [14]. Our aims were to: use a non-compartment pharmacokinetic model to evaluate the disposition of gametocyte sexes and, to develop new indices to evaluate the influence of antimalarials on transmissibility based on the changes in gametocyte sex ratio. We applied the indices to the data on gametocyte sexes collected from a series of antimalarial studies in children treated with various antimalarial drugs in an endemic area of malaria in southwest Nigeria between 1999 and 2006 and compared the agreement between the two indices. 
Table 1. Treatment Regimens of the Children Enrolled in the Study

\begin{tabular}{|c|c|}
\hline Drugs* & Regimens $^{\dagger}$ \\
\hline CQ & $30 \mathrm{mg} / \mathrm{kg}$ of chloroquine base over 3 days, that is, $10 \mathrm{mg} / \mathrm{kg}$ daily \\
\hline AQ & $30 \mathrm{mg} / \mathrm{kg}$ of amodiaquine base over 3 days, that is, $10 \mathrm{mg} / \mathrm{kg}$ daily \\
\hline PS & Pyrimethamine-sulphadoxine given as $25 \mathrm{mg} / \mathrm{kg}$ of the sulphadoxine component at presentation \\
\hline COT & Cotrimoxazole given as $25 \mathrm{mg} / \mathrm{kg}$ of the sulphamethoxazole component twice daily for 5 days \\
\hline AS & Artesunate given as $28 \mathrm{mg} / \mathrm{kg}$ over 7 days, that is, $4 \mathrm{mg} / \mathrm{kg}$ daily \\
\hline PSP & Pyrimethamine-sulphadoxine given as in PS above plus probenecid at $20-25 \mathrm{mg} / \mathrm{kg}$ in two divided doses daily for 3 days \\
\hline $\mathrm{AL}$ & $\begin{array}{l}\text { Artemether (20mg) plus lumefantrine (120mg) given thus: } 5-14 \mathrm{~kg} \text { received } 1 \mathrm{tab}, 15-24 \mathrm{~kg} \text { received } 2 \text { tab., } 25-34 \mathrm{~kg} \text { received } 3 \text { tab., }>34 \mathrm{~kg} \\
\text { received } 4 \mathrm{tab} \text {. at presentation } 8 \mathrm{hr} \text { later and at } 24,36,48 \text { and } 60 \mathrm{hrs} \text { after first dose }\end{array}$ \\
\hline ASAQ & Artesunate given as in AS above plus amodiaquine given as in AQ above \\
\hline ASP & Amodiaquine given as in AQ above plus sulfalene-pyrimethamine given as $25 \mathrm{mg} / \mathrm{kg}$ of the sulfalene component \\
\hline
\end{tabular}

\section{PATIENTS AND METHODS}

\section{Patients}

Patients were recruited from 1999-2006 at the malaria clinic of the University College Hospital in Ibadan, southwest Nigeria, an endemic area of malaria [15] into various antimalarial efficacy studies and were enrolled if the following criteria were met: an age 0.5-14 years, fever or history of fever in the $24-48 \mathrm{~h}$ preceding presentation, pure Plasmodium falciparum parasitaemia $\geq 2000 / \mu 1$ blood, absence of concomitant illness, negative urine tests for 4aminoquinoline (Dill- Glazko) and sulfonamides (lignin), and written informed consent of a parent or guardian. Patients with severe malaria [16] or serious underlying diseases (renal, cardiac or hepatic) or severe malnutrition were excluded from the study. The studies received approval from the local ethics committee.

\section{Drug Management, and Quantification and Determina- tion of Gametocyte Sex}

Drug treatment was according to standard schedules [10, 17, 18] see Table 1 for detail). At enrolment (day 0) and at follow-up on days 1-7, 14, 21, and 28 (up to 2003) and on 1$3,7,14,21,28,35$ and 42 (after 2003), patients underwent full physical examination and thin and thick blood films examination for quantification of asexual and sexual parasitaemia. Quantification of asexual and sexual parasites in thick films was done against 500 and 1000 leukocytes, respectively assuming a leukocyte count of $6000 / \mu \mathrm{l}$ blood. All gametocytes were sexed if gametocytaemia $\geq 10 / \mu 1$ blood and according to the following criteria [19]: males (microgametocytes) are smaller than females (macrogametocytes), the nucleus is larger in males than females, the ends of the cells are rounder in males and angular in females, with Giemsa the cytoplasm stains purple in males and deep blue in females, and the granules of malaria pigment are centrally located in females and more widely scattered in males. The sex ratio was defined as the proportion of gametocytes in peripheral blood that were male [4]. Blood obtained from a finger prick into heparinized capillary tubes was used to estimate the haematocrit.

\section{Kinetics of Sex Specific Gametocytaemia}

Gametocyte kinetic parameters were estimated from gametocyte and sex-specific densities (gametocyte and gametocyte sex concentrations or gametocytaemias) by a non compartment model using the computer programme Turbo Ken (Clinical Pharmacology Group, University of Southampton, UK, through the courtesy of Professor A.G. Renwick) as previously described [12]. Briefly, the following parameters were calculated from the curve of sex specific gametocytaemia by using the real times of sampling from each patient: areas under the curves of gametocytaemia versus time until the last detectable gametocyte concentration $\left(\mathrm{C}_{\mathrm{tgm}}\right)$, $\left(\mathrm{AUC} \mathrm{C}_{\mathrm{gmlast}}\right)$, were calculated using the trapezoidal method. Area under the sex specific gametocytaemiatime from zero to infinity $\left(\mathrm{AUC}_{\mathrm{gm} 0-\infty}\right)$ was calculated by adding to $\mathrm{AUC}_{\mathrm{gmlast}}$ the extrapolated $\mathrm{AUC}_{\mathrm{gm}}$ calculated as $\mathrm{C}_{\mathrm{tgm}} / \mathrm{k}_{\mathrm{el}}$, the elimination rate constant derived from the semilogarithic plot of sex specific gametocytaemia versus time. In this context, visual inspection of the final part of the gametocytaemia-time curve was used to identify the elimination phase. Terminal sex specific elimination half life, $t_{1 / 2 \beta}$, was calculated as $0.693 / \mathrm{k}_{\mathrm{el}}$. The final sex specific gametocytaemia at the apparent time of clearance was taken to be 0.001 sexual forms $/ \mu 1$ blood (a level assumed to be below microscopical detection). Sex specific areas under the curve and half-lives were determined only in patients who had gametocytaemia at enrolment and for at least three times during the first 7-14 days after enrolment.

\section{Definition of New Indices, GMI and GMLI}

Gametocyte maleness index (GMI) was defined as the ratio of sex specific half lives male : female. Gametocyte maleness load index (GMLI) was defined as the ratio of sex specific areas under the curve male : female, that is AUCmg (male gametocyte) : AUC fg (female gametocyte). These ratios were determined for each drug treatment group. Patients participating in GMI and GMLI evaluation were 50 
randomly selected children who had gametocytaemia $>10 / \mu 1$ blood at presentation

\section{DATA ANALYSIS}

Data were analyzed using version 6 of the Epi-Info software [20], the statistical programme SPSS for Windows version 10.01 [21] and MedCalc version 9.4.0.0 [22]. Variables considered in the analysis were related to the densities of $P$. falciparum gametocytes and trophozoites. Proportions were compared by calculating $\chi^{2}$ with Yates' correction or by Fisher exact or by Mantel Haenszel tests. Normally distributed, continuous data were compared by Student's t-tests and analysis of variance (ANOVA). Data not conforming to a normal distribution were compared by the Mann-Whitney U-tests and the Kruskal-Wallis tests (or by Wilcoxon ranked sum test). Association between GMI and GMLI was derived from each patient by correlation analysis and agreement between the two methods of measuring gametocyte maleness was further examined by Altman-Bland analysis [23]. All tests of significances were two-tailed. P-values of $\leq 0.05$ were taken to indicate significant differences. Data were (double)-entered serially using the patients' codes and were only analyzed at the end of the study.

\section{RESULTS}

\section{Patient Characteristics at Enrolment}

The clinical and parasitological characteristics of the children enrolled in the efficacy studies and those from whom the new indices were derived are shown in Table 2. The gametocyte sex ratio in the cohort of 162 children who carried gametocytes at enrolment was $0.18 \pm 0.02$ (SEM, standard error of mean) and in the subset of 52 children in whom GMI and GMLI were evaluated was $0.31 \pm 0.03$ (SEM).

Table 2. Clinical and Parasitological Characteristics of Children Enrolled and those who Met the Criteria for the Gametocyte Maleness Load Index (GMLI) and Gametocyte Maleness Index (GMI)

\begin{tabular}{|c|c|c|}
\hline Characteristic & $\begin{array}{c}\text { Total Children } \\
\text { Enrolled (1999- } \\
\text { 2006) }\end{array}$ & $\begin{array}{c}\text { Children who Participated in } \\
\text { GMLI and GMI Evaluation }\end{array}$ \\
\hline \hline Number
\end{tabular}

All values are mean \pm standard deviation

* Values are geometric mean (range)

$\dagger$ Values are mean \pm standard error of mean

${ }^{\dagger \dagger}$ Patients were randomly selected

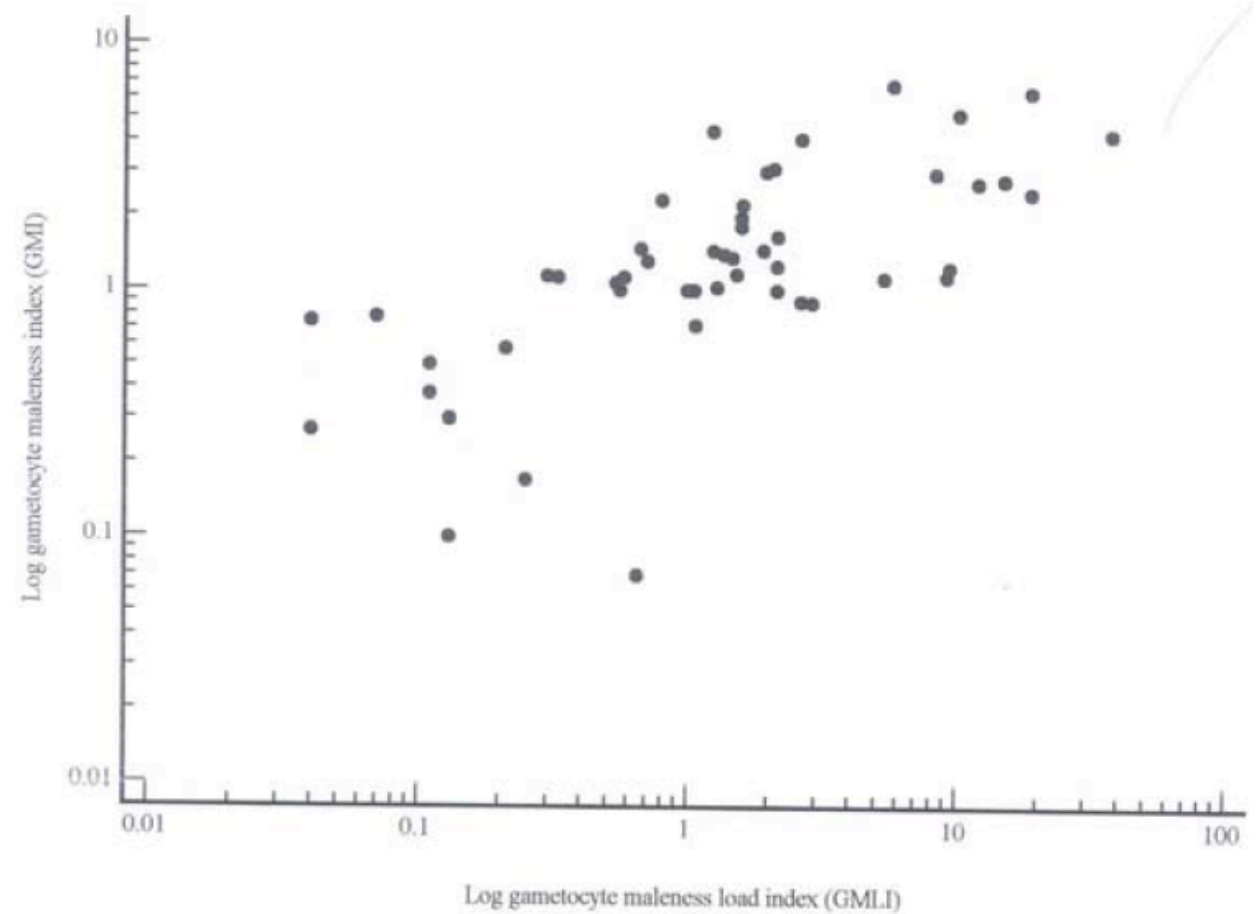

Fig. (1). Scatter plot of log gametocyte maleness index (GMI) and log gametocyte maleness load index (GMLI) in children with falciparum malaria treated with antimalarial drugs $(\mathrm{n}=52, \mathrm{r}=0.71, \mathrm{P}<0.0001)$. 


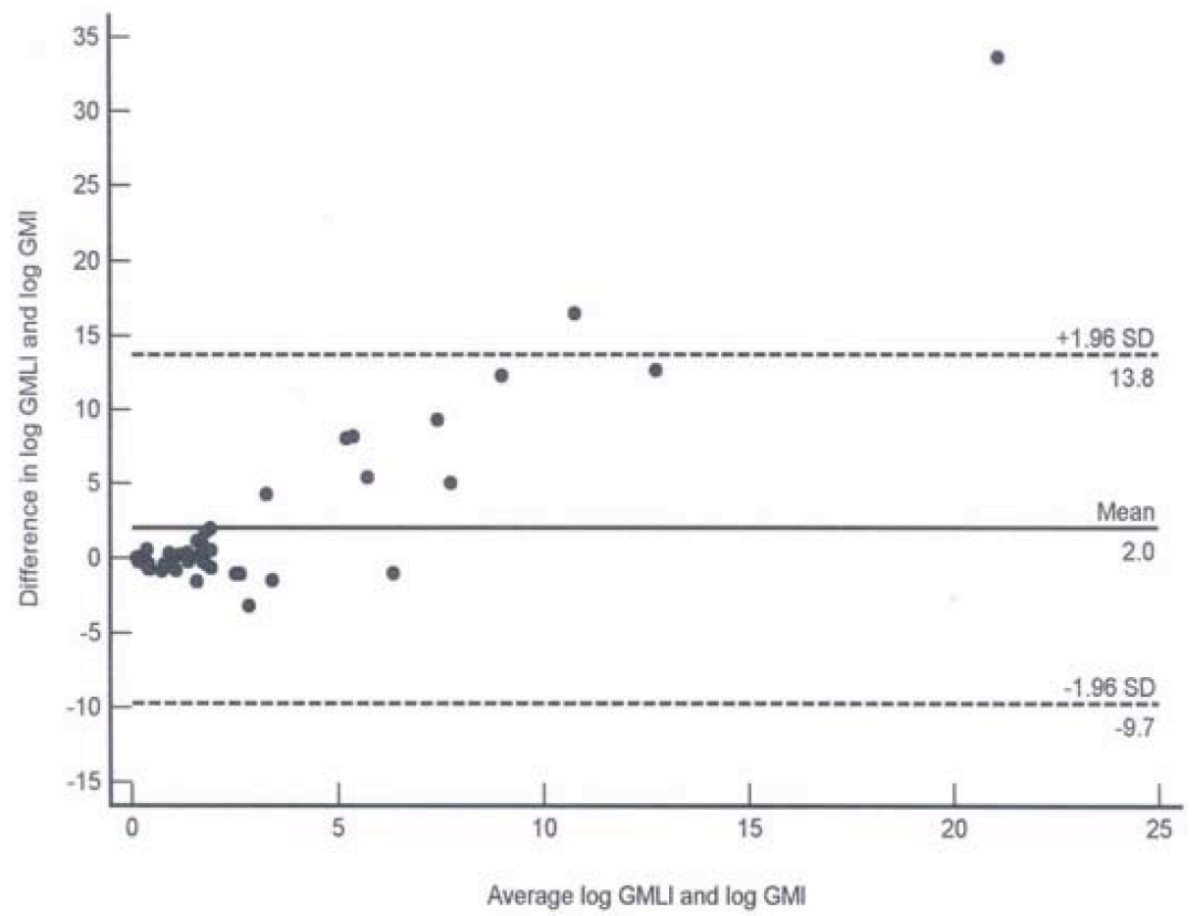

Fig. (2). Altman-Bland plot of log gametocyte maleness index (GMI) and log gametocyte maleness load index (GMLI) in children with falciparum malaria treated with antimalarial drugs. The mean $( \pm$ standard deviation, SD) value of the difference is shown.

\section{Association between GMI and GMLI in Individual Patient}

Fig. (1) is a scatter plot of GMI and GMLI values in patients in whom both data were available. There was a significant correlation between the two methods $(\mathrm{r}=0.71, \mathrm{P}$ $<0.0001, \mathrm{n}=52)$.

\section{Agreement between GMI and GMLI in Individual Patients}

The Altman-Bland plot of the difference between log GMI and log GMLI against the average of both values are shown in Fig. (2). The limit of agreement for the two methods was -9.7 to 13.8 . The $95 \%$ confidence interval (95\%CI for the upper limit of agreement was 10.9 to 16.6 and for the lower limit of agreement was -12.5 to -6.8 .

\section{Drug Related GMI and GMLI}

The GMI and GMLI values for each treatment groups are shown in Tables $\mathbf{3}$ and $\mathbf{4}$, respectively. Because sex specific AUCs (not half-lives) were not normally distributed, geometric mean values are indicated for GMI and GMLI on Tables 3 and 4. In general, values of GMI and GMLI were similar for each drug treatment group, and are significantly correlated $(\mathrm{r}=0.9, \mathrm{P}=0.001)$ and close to unity.

\section{DISCUSSION}

Current methods for the measurement of malarial transmission have not taken into full account the potential of antimalarial drugs to enhance or reduce malaria transmission in endemic communities and have not used models based on pharmacokinetic principles. We have evaluated a kinetic
Table 3. Sex Specific Half-Lives Following Treatment with Antimalarial Drugs and Drug Specific Gametocyte Maleness Index (GMI)

\begin{tabular}{|c|c|c|c|}
\hline $\begin{array}{c}\text { Drug } \\
\text { Treatment }\end{array}$ & \multicolumn{2}{|c|}{ Half-life (days) } & GMI \\
\hline \hline CQ & $0.80(13)$ & $0.33(13)$ & 2.27 \\
& $0.30-1.03$ & $0.13-1.03$ & \\
\hline AQ & $0.74(17)$ & $0.56(17)$ & 1.32 \\
& $0.16-3.77$ & $0.15-1.03$ & \\
\hline \multirow{2}{*}{ PS } & $0.96(5)$ & $0.50(5)$ & 1.92 \\
& $0.55-2.56$ & $0.13-1.12$ & \\
\hline \multirow{2}{*}{ COT } & $0.74(2)$ & $0.30(2)$ & 2.47 \\
& $0.73-0.75$ & $0.14-0.66$ & \\
\hline AS & $0.21(5)$ & $0.67(5)$ & 0.31 \\
& $0.08-0.82$ & $0.31-1.45$ & \\
\hline \multirow{2}{*}{ PSP } & $0.40(3)$ & $0.21(3)$ & 1.90 \\
\hline \multirow{2}{*}{ AL } & $0.08-0.93$ & $0.08-0.34$ & \\
& $0.27(2)$ & $0.59(2)$ & 0.46 \\
\hline ASAQ & $0.08-0.88$ & $0.30-1.17$ & \\
\hline \multirow{2}{*}{ ASP } & $0.74(3)$ & $1.67(3)$ & 0.44 \\
& $0.52-1.03$ & $1.03-3.50$ & \\
\hline $0.15(2)$ & $0.86(2)$ & 0.37 \\
\hline
\end{tabular}

All values are geometric mean (number) range

GMI, gametocyte maleness index defined as the ratio of sex specific half lives male: female

$\mathrm{CQ}$, chloroquine; AQ, amodiaquine; PS, pyrimethamine-sulphadoxine; COT, cotrimoxazole; AS, artesunate; PSP, pyrimethamine-sulphadoxine plus probenecid; $\mathrm{AL}$, artemether plus lumefantrine; ASAQ, artesunate plus amodiaquine; ASP, amodiaquine plus sulfalene-pyrimethamine 
Table 4. Sex Specific AUCs Following Treatment with Antimalarial Drugs and Drug Specific Gametocyte Maleness Index (GMLI)

\begin{tabular}{|c|c|c|c|}
\hline $\begin{array}{c}\text { Drug } \\
\text { Treatment }\end{array}$ & \multicolumn{2}{|c|}{$\begin{array}{c}\text { AUC }\left(\mu \mathbf{I}^{-1} \text {.day) }\right. \\
\text { Microgametocyte Macrogametocyte }\end{array}$} & GMLI \\
\hline \hline CQ & $\begin{array}{c}158(13) \\
12.45-1926.82\end{array}$ & $\begin{array}{c}59(13) \\
6.69-259.89\end{array}$ & 2.68 \\
\hline AQ & $\begin{array}{c}236(17) \\
6.69-3566.06\end{array}$ & $\begin{array}{c}187(17) \\
9.35-2879.80\end{array}$ & 1.26 \\
\hline PS & $\begin{array}{c}1456(5) \\
214.73-4689.95\end{array}$ & $\begin{array}{c}324(5) \\
73.90-2257.23\end{array}$ & 4.49 \\
\hline COT & $\begin{array}{c}231(2) \\
164.33-326.23\end{array}$ & $\begin{array}{c}24(2) \\
17.80-31.84\end{array}$ & 9.62 \\
\hline AS & $\begin{array}{c}27(5) \\
6.69-60.75\end{array}$ & $\begin{array}{c}98(5) \\
10.28-274.26\end{array}$ & 0.28 \\
\hline PSP & $\begin{array}{c}158(3) \\
9.35-881.04\end{array}$ & $\begin{array}{c}26(3) \\
9.35-46.35\end{array}$ & 6.08 \\
\hline AL & $\begin{array}{c}7(2) \\
0.68-66.75\end{array}$ & $15.61-1801.02$ & 0.04 \\
\hline ASAQ & $\begin{array}{c}94(3) \\
51.29-190.22\end{array}$ & $\begin{array}{c}661(3) \\
400.89-1485.30\end{array}$ & 0.14 \\
\hline ASP & $\begin{array}{c}35(2) \\
18.35-66.74\end{array}$ & $\begin{array}{c}256(2) \\
72.66-902.56\end{array}$ & 0.14 \\
\hline
\end{tabular}

All values are geometric mean (number) range

AUC, area under the curve of gametocytaemia versus time; GMLI, gametocyte maleness load index, defined as the ratio of sex specific AUC male: female; CQ, chloroquine; AQ, amodiaquine; PS, pyrimethamine-sulphadoxine; COT, cotrimoxazole; AS, artesunate; PSP, pyrimethamine-sulphadoxine plus probenecid; AL, artemether plus lumefantrine; ASAQ, artesunate plus amodiaquine; ASP, amodiaquine plus sulfalene-pyrimethamine

approach to malaria transmission based on the assumption that gametocyte sex ratio is crucial to mosquito infectivity and derived two new indices for quantification of the potential of antimalarial drugs to enhance or reduce malaria transmission in endemic communities. Our methods have distinct advantages: they employed the levels of gametocyte found in peripheral blood over a relatively long period of time and allow a quantitative approach; the sampling periods far exceeded the estimated gametocyte sequestration time of 4 days in vivo in patients not previously exposed to malaria [24] and the average estimated half life of gametocytaemia in children resident in endemic areas [10-12]. Additionally, the methods allow assessment of the effects of each drug on gametocyte sexes and their application is independent of any definition of a male-biased sex ratio. It is noteworthy that the software for pharmacokinetic analyses of half life and areas under the curves of gametocyte density versus time are readily available. The main drawback of the methods is that they require careful follow up of patients over a period of 12 weeks, a situation that may be difficult in patients who self medicate. In addition only subjects in whom there was gametocytaemia at enrolment could be used to calculate these indices. A population pharmacokinetic approach may be applied to resolve the problems posed by the last.

The most important findings of the present study are the wide range of the $95 \%$ CI for agreement between the pharmacokinetic indices at the individual level and the considerable agreement for the estimation of the effects of antimalarial drugs at the group level. The clinical significance of the discrepancy between the two methods at the individual and group levels is unclear. The narrow limits of agreement between the two methods at the group level would suggest that either method is sufficiently reliable for independent use. However, it is our opinion that GMI has less variation and may be a relatively simpler method to use.

Both the half life and the area inscribed by the plot of gametocyte density against time are kinetically related. However, $\mathrm{AUC}_{\text {gmsexes }}$ is a quantitative measure of load carried over a period of time. In this context, it is a measure of investment, and when related to gametocytes, relative investment in the sexes. Thus it has been suggested [18] that in areas of intense transmission and depending on the availability of both gametocyte sexes, it is likely that the proportion of mosquitoes which become infected following a blood meal after treatment may be related to the $\mathrm{AUC}_{\mathrm{gm}}$ providing both gametocyte sexes are available and viable. This proportion may also be expected to be high if more male gametocytes are present in the blood meals. Thus high GMLI after treatment may provide a quantitative estimate of the influence of drugs on the potentials for transmissibility.

Analyses of drug-related effects using the values of derived from both methods were similar. In this context, the data suggest that $P$. falciparum, when exposed to antimalarials, which threatens its survival invest in gametocyte sex ratio following treatment with 4-aminoquinolines and antifolates. In addition these drugs also increases gametocytaemia and carriage $[11,25,26]$ suggesting investment in gametocytes. By contrast treatment with artesunate and ACTs was not associated with investment in gametocytes or sex ratio. These findings would suggest antimalarials have differing effects on the responses of $P$. falciparum on its survival strategies.

\section{ACKNOWLEDGEMENTS}

The antimalarial efficacy studies from which the sex ratio studies were derived received financial support from The UNDP/World Bank/ WHO Special Programme for Research and Training in Tropical Diseases through the Career Development Grant awarded to AS. The AL and ASP efficacy study received financial support from Pfizer Global Pharmaceuticals. We thank our clinic staff, especially Moji Amao, Adeola Alabi, and Bose Shoyoye for assistance with running the studies.

\section{CONFLICT OF INTEREST}

None Declared.

\section{REFERENCES}

[1] Tchuinkam T, Mulder B, Dechering K, et al. Experimental infections of Anopheles gambiae with Plasmodium falciparum of naturally infected gametocyte carriers in Cameroon: factors influencing the infectivity to mosquitoes. Trop Med Parasitol 1993; 44: $271-6$.

[2] Robert V, Read AF, Essong J, et al. Effects of gametocyte sex ratio on infectivity of Plasmodium falciparum to Anopheles gambiae. Trans R Soc Trop Med Hyg 1996; 90: 621-4.

[3] Robert V, Sokhna CS, Rogier C, et al. Sex ratio of Plasmodium falciparum gametocytes in inhabitants of Dielmo, Senegal. Parasitology 2003; 127: 1-8. 
[4] Pickering J, Read AF, Guerrero S, et al. Sex ratio and virulence in two species of lizard malaria parasites. Evol Ecol Res 2000; 2: 17184.

[5] Hogh B, Gamage-Mendis A, Butcher GA, et al. The differing impact of chloroquine and pyrimethamine/sulfadoxine upon the infectivity of malaria species to its vector. Am J Trop Med Hyg 1998; 58: 176-82.

[6] Drakeley CJ, Jawara M, Targett GAT, et al. Addition of artesunate to chloroquine for the treatment of Plasmodium falciparum malaria in Gambian children causes a significant but short-lived reduction in infectiousness to mosquitoes. Trop Med Inter Health 2003; 9: 53-61.

[7] Bousema JT, Schneider P, Gougna LC, et al. Moderate effect of artemisinin based combination therapy on transmission of Plasmodium falciparum. J Infect Dis 2006; 193: 1151-9.

[8] Reece SE, Duncan AB, West SA, et al. Host cell preference and variable transmission strategies in malaria parasites. Proc R Soc B 2005; 272: 511-7

[9] Buckling AGJ, Ranford-Cartwright L, Miles A, et al. Chloroquine increases Plasmodium falciparum gametocytogenesis in vitro. Parasitol 1999; 118: 339-46.

[10] Sowunmi A, Fateye BA. Plasmodium falciparum gametocytaemia in Nigerian children: before, during and after treatment with antimalarial drugs. Trop Med Inter Health 2003; 8: 783-92.

[11] Sowunmi A, Fateye BA. Gametocyte sex ratios in children with asymptomatic, recrudescent, pyrimethamine-sulfadoxine-resistant Plasmodium falciparum malaria. Ann Trop Med Parasitol 2003; 97: 671-82.

[12] Sowunmi A, Fateye BA. Changes in Plasmodium falciparum gametocytaemia in children with chloroquine-sensitive asexual infections. Parasite 2003; 10: 363-9.

[13] Bonnet S, Gouagna LC, Paul RE, et al. Estimation of malaria transmission from humans to mosquitoes in two neighbouring villages in south Cameroon: evaluation and comparison of several indices. Trans R Soc Trop Med Hyg 2003; 97: 53-9.

[14] Mitri C, Thiery I, Bourgouin C, et al. Density-dependent impact of the human malaria parasite Plasmodium falciparum gametocyte sex ratio on mosquito infection rates. Proc R Soc Lond Series B 2009; 276: 3721-6.

[15] Salako LA, Ajayi FO, Sowunmi A, et al. Malaria in Nigeria: a revisit. Ann Trop Med Parasitol 1990; 84: 435-45.

[16] World Health Organization. Severe falciparum malaria. Trans R Soc Trop Med Hyg 2000; 94 (Suppl 1): 1-90.

[17] Sowunmi A, Balogun T, Gbotosho GO, et al. Activities of amodiaquine, artesunate, and artesunate-amodiaquine against asexual- and sexual-stage parasites in falciparum malaria in children. Antimicrob Agents Chemother 2007; 51: 1694-9.

[18] Sowunmi A, Balogun T, Gbotosho GO, et al. Activities of artemether-lumefantrine and amodiaquine-sulfalene-pyrimethamine against sexual-stage parasites in falciparum malaria in children. Chemotherapy 2008; 54: 201-8.

[19] Carter R, Graves PM. Gametocytes. In: Wernsdorfer WH, McGregor I, Eds., Malaria: Principles and Practice of Malariology, Edingburgh: Churchill Livingstone 1988; vol. 1: 253-303.

[20] Epi Info Version 6. A Word Processing Data Base and Statistics Program for Public Health on IBM-compatible Microcomputers. Atlanta, GA, Centers for Disease Control and Prevention 1994.

[21] SPSS for Windows Release 10.01 (Standard Version). SPSS Inc., Chicago, IL, SPSS Inc. 1999.

[22] MedCalc for Windows Version 9.4.0.0. Statistics for Biomedical Research. Broekstraat, Belgium. 1993.

[23] Bland JM, Altman DG. Statistical methods for assessing agreement between two methods of clinical measurement. Lancet 1986; i: 307-10.

[24] Eichner M, Diebner HH, Molineaux L, et al. Genesis, sequestration and survival of Plasmodium falciparum gametocytes: parameter estimates from fitting model to malariotherapy data. Trans R Soc Trop Med Hyg 2001; 95, 297-301.

[25] Sowunmi A, Fateye BA, Adedeji AA, et al. Effects of antifolatescotrimoxazole and pyrimethamine-sulfadoxine on gametocytes in children with acute, symptomatic, uncomplicated Plasmodium falciparum malaria. Mem Inst Oswaldo Cruz 2005; 100: 451-5.

[26] Sowunmi A, Balogun ST, Gbotosho GO et al. Plasmodium falciparum gametocyte sex ratios in symptomatic children treated with antimalarial drugs. Acta Tropica 2009; 109: 108-17.

Received: May 25, 2011

Revised: June 19, 2011

Accepted: June 25, 2011

(C) Gbotosho et al.; Licensee Bentham Open.

This is an open access article licensed under the terms of the Creative Commons Attribution Non-Commercial License (http://creativecommons.org/licenses/by$\mathrm{nc} / 3.0 /$ ), which permits unrestricted, non-commercial use, distribution and reproduction in any medium, provided the work is properly cited. 